\title{
Antiviral and Inflammatory Cellular Signaling Associated with Enterovirus 71 Infection
}

\author{
Yuefei Jin ${ }^{1}$ (D), Rongguang Zhang ${ }^{1}$, Weidong $W^{2}{ }^{2}$ and Guangcai Duan ${ }^{1, *}$ \\ 1 Department of Epidemiology, College of Public Health, Zhengzhou University, Zhengzhou 450001, China; \\ jinyuefeixuanchuan@163.com (Y.J.); zrg@zzu.edu.cn (R.Z.) \\ 2 Department of Occupational and Environmental Health, School of Public Health, Xinxiang Medical \\ University, Xinxiang 453003, China; wdwu2013@126.com \\ * Correspondence: gcduan@zzu.edu.cn
}

Received: 1 February 2018; Accepted: 24 March 2018; Published: 28 March 2018

\begin{abstract}
Enterovirus 71 (EV71) infection has become a major threat to global public health, especially in infants and young children. Epidemiological studies have indicated that EV71 infection is responsible for severe and even fatal cases of hand, foot, and mouth disease (HFMD). Accumulated evidence indicates that EV71 infection triggers a plethora of interactive signaling pathways, resulting in host immune evasion and inflammatory response. This review mainly covers the effects of EV71 infection on major antiviral and inflammatory cellular signal pathways. EV71 can activate cellular signaling networks including multiple cell surface and intracellular receptors, intracellular kinases, calcium flux, and transcription factors that regulate antiviral innate immunity and inflammatory response. Cellular signaling plays a critical role in the regulation of host innate immune and inflammatory pathogenesis. Elucidation of antiviral and inflammatory cellular signaling pathways initiated by EV71 will not only help uncover the potential mechanisms of EV71 infection-induced pathogenesis, but will also provide clues for the design of therapeutic strategies against EV71 infection.
\end{abstract}

Keywords: EV71; antiviral innate immunity; cellular signaling; immune evasion; inflammatory response

\section{Introduction}

Enterovirus 71 (EV71), a member of the Picornaviridae family, is known to cause hand, foot, and mouth disease (HFMD) worldwide [1,2]. The viral particle of EV71 consists of a non-enveloped capsid surrounding a core of single-stranded, positive-polarity RNA of approximately $7.5 \mathrm{~kb}$ in size, which encodes the structural protein P1 and the non-structural proteins P2 and P3 [1,3]. The cleavage of P1 by the viral protease 3CD leads to the release of the capsid proteins VP0 (VP4 + VP2), VP3, and VP1, which subsequently leads to the assembly of the viral capsid. The cleavage of $\mathrm{P} 2$ and $\mathrm{P} 3$ by the viral protease leads to the release of seven non-structural proteins: $2 \mathrm{~A}-2 \mathrm{C}$ and $3 \mathrm{~A}-3 \mathrm{D}$. The structure of the EV71 genome is shown in Figure 1. The viral capsid is composed of 60 identical protomers, each consisting of the four structural proteins: VP1-VP4 [1,3]. The proteins VP1, VP2, and VP3 of EV71 are largely exposed on the outer surface of the capsid, while the protein VP4 together with the N-terminus of VP1 decorate the inner surface of the capsid shell in a mature virion [3,4]. 


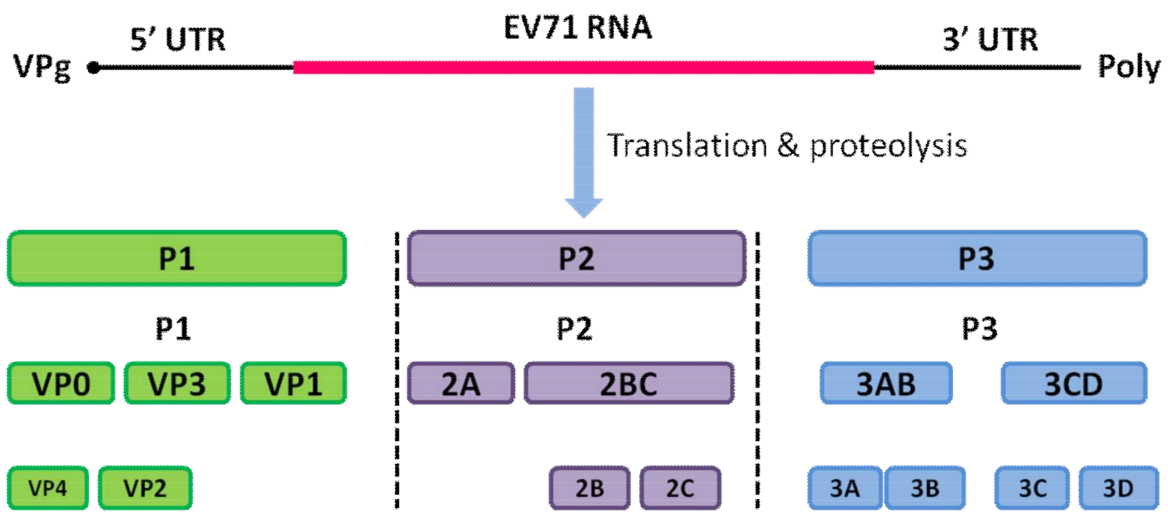

Figure 1. Structure of the enterovirus 71 (EV71) genome. The highly structured 5' UTR and 3' UTR followed by the poly (A) tail control the viral protein translation by binding to the viral VPg protein. This is followed by proteolytic cleavage, and the original protein is matured into four structural proteins, VP1-VP4, and seven non-structural proteins, 2A-2C and 3A-3D.

When an EV71 infection occurs, inflammation is known to play a critical role in the development of the host infection. This is always characterized by an infiltration of inflammatory cells, a release of pro-inflammatory cytokines and chemokines, edema, and vascular leakage [5]. It has been widely appreciated that EV71 infection can result in complex inflammation on the sites of EV71 replication accompanied by immune evasion, multiple immune cell responses, and proinflammatory cytokine release $[1,6-10]$. There have also been successes in antiviral and anti-inflammatory therapies in vivo for clinical patients with an EV71 infection [11,12]. It has been reported that many cellular signaling pathways are involved in EV71 replication and EV71-induced inflammatory pathogenesis $[6,11,13,14]$. Hence, characterization of EV71-induced cellular signaling is expected to provide useful information for uncovering the mechanisms of the complicated outcomes of HFMD, and aid in the design of therapeutic strategies against EV71 infection. In this review, we mainly focus on the major cellular signaling pathways involved in EV71-induced antiviral innate immune and inflammatory responses.

\section{Oxidative Stress Mediates EV71-Induced Signaling}

Oxidative stress (OS) is known to take place when the generation of reactive oxygen species (ROS) overwhelms cellular antioxidant defenses [15]. Accumulated evidence indicates that ROS play a central role in the determination of the fate of a cell as second messengers which modify various signaling molecules [16]. EV71-induced generation of ROS is essential for viral replication in host cells $[7,17]$. A previous study has demonstrated that mitochondria are a major source of ROS in EV71-infected cells [17]. Glucose-6-phosphate dehydrogenase (G6PD) deficient cells, which have limited antioxidant capacity, exhibit susceptibility to EV71 replication and have a greater cytopathic effect (CPE), loss of viability, and upregulation of nuclear factor-kappa B (NF- $\mathrm{KB}$ ) signaling [18]. Some in vitro intervention experiments confirm that EV71 infection-induced ROS production can activate multiple inflammatory signaling pathways. Schizonepeta tenuifolia Briq, a herbal constituent of traditional Chinese medicine, was shown to inhibit ROS formation and the resultant p38 kinase activation induced by EV71 infection [19]. Curcumin was also reported to reduce the production of ROS induced by EV71 infection and ROS-mediated activation of extracellular regulated protein kinases (ERK) [20]. Additionally, it was demonstrated that apigenin treatment suppresses intracellular ROS production and Jun N-terminal kinase (JNK) activation induced by EV71 infection [21]. Based on these studies, ROS formation is likely to be one biological mechanism leading to EV71 infection-induced inflammatory response (see Figure 2). In terms of these results, antioxidant drugs may be useful to treat EV71 infection-associated HFMD. Of course, these studies are also controversial. 


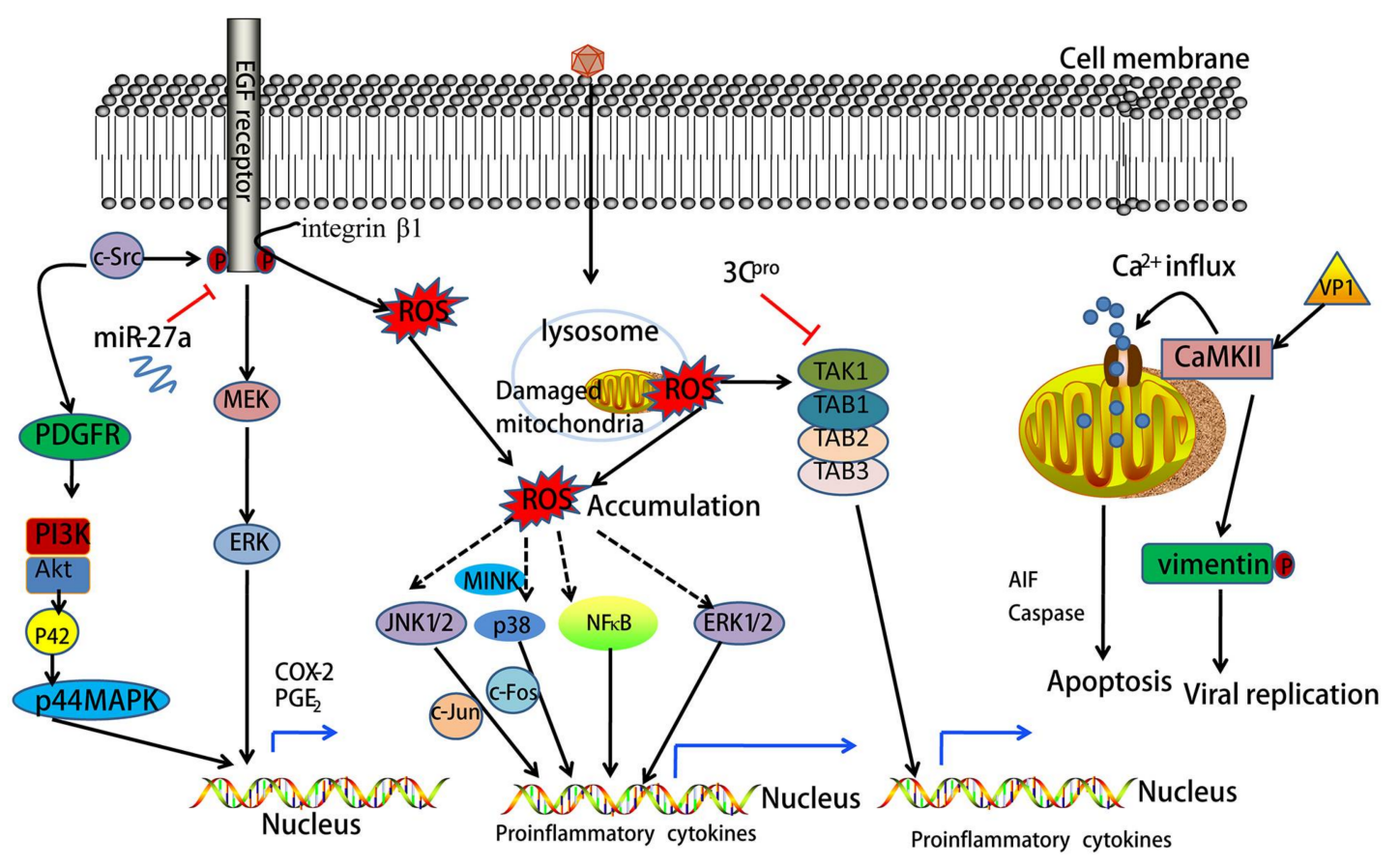

Figure 2. EV71 induces multiple cellular inflammatory signals and $\mathrm{Ca}^{2+}$-dependent signals. Epidermal growth factor receptor (EGFR)-dependent signaling plays an important role in the pathogenesis of inflammation through regulation of pro-inflammatory genes. EV71 infection induces cyclooxygenase-2 $(\mathrm{COX}-2)$ and prostaglandin $\mathrm{E} 2\left(\mathrm{PGE}_{2}\right)$ overexpression through the c-Src/EGFR/MEK/ERK and c-Src/PDGFR/PI3K/Akt/p42/p44MAPK signal pathways. The activation of EGFR can be blocked by miR-27a. EV71 infection causes reactive oxygen species (ROS) accumulation through the integrin $\beta 1$ /EGFR signals and mitochondrial damage. ROS activate JNK1/2, p38, ERK1/2, and nuclear factor-kappa B (NF- $\mathrm{B}$ ) directly or indirectly, and further regulate the production of multiple proinflammatory cytokines. EV71-encoded $3 \mathrm{C}$ protease $\left(3 \mathrm{C}^{\mathrm{pro}}\right)$ inhibits pro-inflammatory cytokine gene transcription through interactions with TAK1/TAB1/TAB2/TAB2 complexes. EV71 initiates $\mathrm{Ca}^{2+}$-dependent signaling, and $\mathrm{Ca}^{2+}$ influx. Additionally, EV71 induces host cell apoptosis by eliciting the apoptosis-inducing factor (AIF), Caspase-independent apoptotic pathway in mitochondria. The EV71 protein VP1 activates calmodulin-dependent protein kinase II (CaMKII) and further phosphorylates Vimentin, which facilitates EV71 replication.

\section{EV71-Encoded Proteases Block Retinoic Acid-Inducible Gene I (RIG-I)-Like Receptor (RLR)-Dependent Antiviral Signaling}

RLRs are cytoplasmic sensors for recognizing double-stranded RNA (dsRNA) during antiviral innate immunity in mammalian cells. Thus far, three members of RLRs have been identified: RIG-I, MDA5, and LGP2 (laboratory of genetics and physiology 2), which all have similar structures. MDA5 and RIG-I consist of three distinct domains: an N-terminal tandem caspase activation and recruitment domain (CARD), a central DExD/H box RNA helicase domain, and a C-terminal domain (CTD) [22,23]. The CARDs are used to interact with the mitochondrial antiviral-signaling adaptor protein (MAVS) to trigger downstream signaling. LGP2 lacks this domain and fails in signal transduction. The main function of the latter two domains is to recognize viral dsRNA and initiate antiviral responses through the transcription of interferon (IFN)- $\alpha / \beta$ [24]. Emerging evidence suggests that innate immune responses elicited by an EV71 infection are modulated by RLR-dependent mechanisms [25-28]. EV71-encoded 3C protease (3C ${ }^{\text {pro }}$ ) has been shown to inhibit RIG-I-mediated IFN- $\alpha / \beta$ response, which may contribute to the pathogenesis of EV71 infection [25]. Another study indicates that EV71 employs EV71-encoded 2A pro to proteolytically target MDA5, further blocking IFN- $\alpha / \beta$ transcription [29]. It is known that microRNAs play a key role in the regulation of innate immune response in multiple cell types [30]. Xu et al. found that EV71-encoded 
3C pro inhibited RIG-I-dependent innate immune response through the down-regulation of miR-526a [27]. All-trans retinoic acid (ATRA), a retinoic acid receptor-a (RAR-a) antagonist, was reported to act on RIG-I signaling against EV71 infection [31]. Whether ATRA is beneficial for EV71 infection-associated HFMD should be demonstrated in the near future. One member of the arrestin family, ARRDC4, has a critical role in glucose metabolism and G-protein-coupled receptor (GPCRs)-related physiological and pathological processes [32]. Meng et al. reported that ARRDC4 interacts with MDA5 via the arrestin-like $\mathrm{N}$ domain, and further recruits TRIM65 to enhance the K63 ubiquitination of MDA5, resulting in the induction of proinflammatory cytokines during EV71 infection [33]. The interaction between ARRDC4 and MDA5 may provide a novel strategy in antiviral drugs development. Taken together, RIG-I signaling blocked by EV71-encoded $3 C^{\text {pro }}$ and $2 A^{\text {pro }}$ provides the molecular mechanism for innate immune evasion during EV71 infection (see Figure 3).

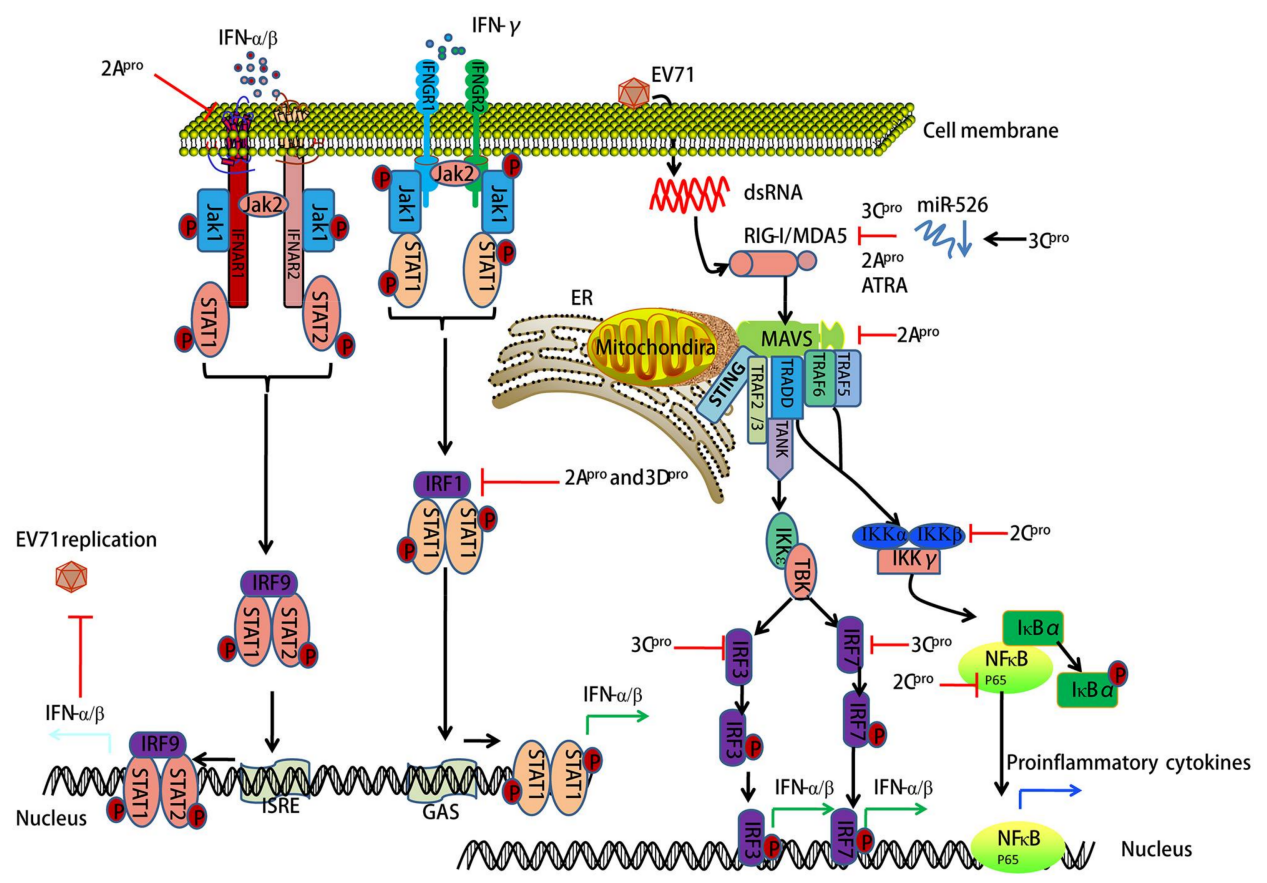

Figure 3. EV71 inhibits host antiviral innate immunity by targeting IFN, interferon regulatory factor (IRF), and retinoic acid-inducible gene I (RIG-I)-like receptors (RLR)-mediated signaling pathways. Antiviral innate immunity plays a critical role in EV71 infection-induced pathogenesis. EV71-encoded 2A pro, 3D pro, $3 C^{\text {pro }}$, and 2C ${ }^{\text {pro }}$ inhibit IFN/STAT (signal transducer and activator of transcription)-mediated type I IFN responses by blocking IFNAR1, IRF-dependent signaling, and by targeting RIG-I, MDA5, MAVS (mitochondrial antiviral-signaling adaptor protein), IKK $\beta$, and NF- $\mathrm{B}$ (p65). On mitochondrial membranes, MAVS is regulated by RLRs such as RIG-I and MDA5, which then interact with the stimulator of interferon genes (STING), the TNF receptor associated factor (TRAF) 2/3, the TNF receptor type 1-associated DEATH domain protein (TRADD), TRAF6, and TRAF5. This process further regulates downstream IKB kinase (IKK) $\varepsilon / T B K 1$ and canonical NF- $\kappa B$ signaling. Canonical NF- $\kappa B$ signaling occurs as the IKK complex, consisting of IKK $\alpha, \operatorname{IKK} \beta$ and $\operatorname{I\kappa B} \alpha$, resulting in the proteasomal degradation of NF- $\kappa B$ inhibitor- $\alpha(\operatorname{I} \kappa B \alpha)$ and thus liberating NF- $\kappa B$ to translocate into the nucleus and initiate pro-inflammatory cytokine gene expression. $3 C^{\text {pro }}$ suppresses RIG-I-dependent innate immune responses through down-regulating miR-526. All-trans retinoic acid (ATRA) is a retinoic acid receptor-a (RAR-a) antagonist, which promotes RIG-I signaling against EV71 infection. ER, endoplasmic reticulum.

\section{EV71-Encoded Proteases Inhibit MAVS-Mediated Antiviral Signaling}

MAVS is comprised of 540 amino acids that form three functional domains: an N-terminal CARD (amino acids 10-77), a proline-rich region (amino acids 107-173), and a C-terminal transmembrane 
segment (amino acids 514-535) [34]. The CARD of MAVS interacts with the CARDs of RIG-I and MDA5, and this interaction is essential for the activation of nuclear factor-kappa B (NF-kB) and the interferon regulatory factor (IRF) signaling pathways for the regulation of pro-inflammatory cytokine and IFN- $\alpha / \beta$ production. Activation of IFN signaling has potent antiviral and growth-inhibitory effects. Previous studies have presented convincing evidence that EV71-derived protease interacts with MAVS-dependent downstream signals. For example, EV71-derived protease $2 \mathrm{~A}^{\text {pro }}$ was shown to suppress IRF3 signaling by cleaving MAVS, which is followed by the shutdown of IFN- $\alpha / \beta$ production [29]. Similarly, another study showed that during EV71 infection MAVS was cleaved by EV71 2A $\mathrm{A}^{\text {pro }}$ and released from the mitochondria, leading to the inhibition of antiviral IFN response [35]. Thus, MAVS-mediated antiviral signaling provides the molecular mechanisms for innate immune evasion during EV71 infection (see Figure 3).

\section{EV71 Infection-Associated IFN Signaling}

Type I IFNs $($ IFN- $\alpha / \beta)$ and type II IFN (IFN- $\gamma$ ) are widely expressed cytokines. These cytokines form the first line of defense against viral infections and also have important roles in immunosurveillance for malignant cells [36]. IFN- $\alpha / \beta$ bind to common cell-surface receptors, known as the type I IFN receptors (IFNAR1 and IFNAR2), while IFN- $\gamma$ binds to different type II IFN receptors (IFNGR1 and IFNGR2) [36]. The binding of IFN- $\alpha / \beta$ to the type I IFN receptors or IFN- $\gamma$ to the type II IFN receptors results in the rapid autophosphorylation and activation of Janus-activated kinase (Jak)/signal transducer and activator of transcription (STAT) pathways [37]. Activation of STATs is a common response to IFN- $\alpha / \beta$ binding [37]. Interestingly, it has been reported that EV71 infection could block IFN-mediated phosphorylation of STAT1, STAT2, Jak1, and Tyk2 through EV71-2A ${ }^{\text {pro }}$-induced IFNAR1 reduction [38]. Another study showed that EV71-encoded $2 \mathrm{~A}^{\text {pro }}$ and $3 D^{\text {pro }}$ block IFN- $\gamma$-induced IRF1 transactivation following a loss of STAT1 nuclear translocation. However, no influence was detected in IFN-receptor expression [39]. Type I and II IFN receptor deficiency increases the mortality of mice upon EV71 infection [40]. Several targets of EV71 infection such as RIG-I, MDA5, MAVS, toll-like receptor (TLR)9, TLR7 and miR-146a were also reported to interact with Type I IFN responses $[13,25,29,41]$. Thus, documented evidence suggests that IFN-mediated signaling pathways play an important role in host antiviral innate immunity against EV71 (see Figure 3).

\section{EV71 Interacts with IRF Signaling}

The IRF family consists of nine members in mammals, which were identified in the late 1980s in the context of research into the type I IFN system [42]. Numerous studies over the past two decades have shown the versatile and critical functions of IRFs [42]. Indeed, IRF signaling-mediated type I IFN and IFN-inducible genes play central roles in the response to pathogen-derived danger signals [43]. The 3Cpro of EV71 has been demonstrated to block RIG-I-mediated IRF3 activation and IFN- $\alpha$ / $\beta$ production [25]. Similarly, EV71 inactivates IRF3 and drastically suppresses IFN-stimulated gene expression [26]. On the contrary, one study showed that IRF3 was activated and translocated into the nucleus in HT-29 cells after EV71 infection [44]. Additionally, EV71-encoded 3C ${ }^{\text {pro }}$ has been proposed to mediate cleavage of IRF7 rather than IRF3 [45]. These inconsistencies remain to be clarified. Taken together, IRF signaling is involved in EV71 infection-induced host antiviral innate immunity (see Figure 3).

\section{EV71 Triggers NF- $k B$ Signaling}

NF- $k B$ is a transcription factor of the Rel family that consists of five members in mammalian cells, e.g., RelA (p65), RelB, Rel (c-Rel), NF-kB1 (p50/p105), and NF-kB2 (p52/p100) [46]. Generally, in response to extracellular or intracellular sensors, NF- $\kappa B$ family proteins integrate multiple stress stimuli to modulate gene expression events that further act on cell survival, differentiation, proliferation, adhesion, immunity, and inflammation [47,48]. Emerging evidence has indicated that NF- $\mathrm{KB}$ signaling is essential for EV71 replication and EV71-induced inflammatory responses [49-52]. 
EV71 infection activates NF- $\mathrm{kB}$ signaling and further regulates multiple inflammatory cytokines in different cell types [49-53]. In vascular smooth muscle cells, EV71-stimulated degradation of NF- $k B$ inhibitor- $\alpha(\mathrm{I} \kappa \mathrm{B} \alpha)$ and translocation of NF- $\mathrm{KB}$ into the nucleus and resultant vascular cell adhesion molecule-1 (VCAM-1) mRNA expression was blocked by a selective NF- $\mathrm{kB}$ inhibitor (helenalin) [52]. EV71 $2 C^{\text {pro }}$ inhibits NF- $\mathrm{KB}$ activation by either binding to the IPT domain of p65 and reducing the formation of heterodimer p65/p50 [54] or through association with IKK $\beta$ [54]. Additionally, resveratrol-a major active component in Polygonum cuspidatum with anti-inflammatory, antioxidant, and antitumor functions-was reported to inhibit EV71 replication and cytokine secretion (e.g., IL-6 and TNF- $\alpha$ ) in rhabdomyosarcoma (RD) cells through blocking IKKs/NF- $k B$ activation [55]. Thus, NF- $\mathrm{KB}$ signaling plays a critical role in EV71-induced inflammatory response and provides a potential antiviral strategy (see Figures 2 and 3).

\section{EV71 Interacts with TLR Signaling}

Recent studies have provided strong evidence that the EV71-induced innate immune response is mediated by the engagement of specific TLRs [13,44]. Currently, 13 mammalian TLRs, expressed on the cell surface or in the endoplasmic reticulum (ER)/endosomal compartments have been identified. Cell surface TLRs (e.g., TLR1, TLR2, TLR4, TLR5, TLR6 and TLR11) sense lipids, lipoproteins, or peptidoglycans from bacteria, fungi, or protozoa, namely pathogen-associated molecular patterns (PAMPs). Intracellular TLRs (e.g., TLR3, TLR7, TLR8 and TLR9) detect bacterial and viral nucleic acids, termed damage-associated molecular patterns (DAMPs) [56]. An in vitro study showed that TLR/Toll/IL-1 Receptor domain-containing adaptor inducing IFN- $\beta$ (TRIF)-signaling is essential to induce IFN- $\alpha / \beta$ in human intestinal epithelial cells infected with EV71 [44]. EV71 3C ${ }^{\text {pro }}$ inhibits the induction of innate immunity by blocking TRIF in response to TLR3 activation [26]. EV71 virus-like particles trigger the activation and maturation of dendritic cells (DCs) by inducing I $\mathrm{kB} \alpha$ degradation and NF-KB activation through TLR4 [57]. Song et al. reported that increased EV71 replication induced by autophagy in $16 \mathrm{HBE}$ cells promotes the degradation of the endosome and leads to the suppression of the TLR7-mediated type I IFN response [41]. Hepatocyte growth factor-regulated tyrosine kinase substrate (HRS) regulates the ESCRT-0 complex and endosomal sorting of membrane proteins. HRS facilitates the TLR7/NF- $\mathrm{KB} / \mathrm{p} 38$ and TLR7/NF- $\mathrm{KB} / \mathrm{IRF} 3$ signaling pathways to produce proinflammatory cytokines and interferons during EV71 infection, which leads to the induction of inflammatory immune responses [58]. In vitro and in vivo studies have demonstrated that TLR9 signaling can provide protection against EV71 infection in response to DAMPs (endogenous DNA) [13]. Moreover, a related study found that the expression levels of TLR3, TLR4, TLR7, and TLR8 mRNA in peripheral blood mononuclear cells (PBMCs) of children with severe HFMD were significantly higher than those with mild symptoms [59]. In contrast, Gong et al. [60] showed upregulation of TLR2, TLR7, and TLR8 mRNA rather than TLR3, TLR4, TLR6, TLR9, or TLR10 at different time points in EV71-infected human primary monocyte-derived macrophages (MDMs). These results suggest that TLR signaling interacts with EV71 infection (see Figure 4 and Table 1).

Table 1. EV71 infection-associated toll-like receptors (TLRs). Abbreviations employed: monocyte-derived macrophages (MDMs), peripheral blood mononuclear cells (PBMCs), DCs, plasmacytoid dendritic cells (pDCs).

\begin{tabular}{ccccc}
\hline TLRs & Ligand & Cell Type & Species & References \\
\hline TLR? & No data & Intestinal epithelial cells & Human & {$[44]$} \\
TLR2 & No data & MDMs & Human & {$[60]$} \\
TLR3 & No data & DCs, PBMCs & Mouse, Human & {$[26,60]$} \\
TLR4 & PAMPs (dsRNA?) & DCs, PBMCs & Mammalian cells, Human & {$[57,60]$} \\
TLR7 & DAMPs? & 16HBE, MDMs, PBMCs & Human & {$[41,58,60]$} \\
TLR8 & No data & MDMs & Human & {$[60]$} \\
TLR9 & Endogenous DNA & pDCs & Mouse & {$[13]$} \\
\hline
\end{tabular}




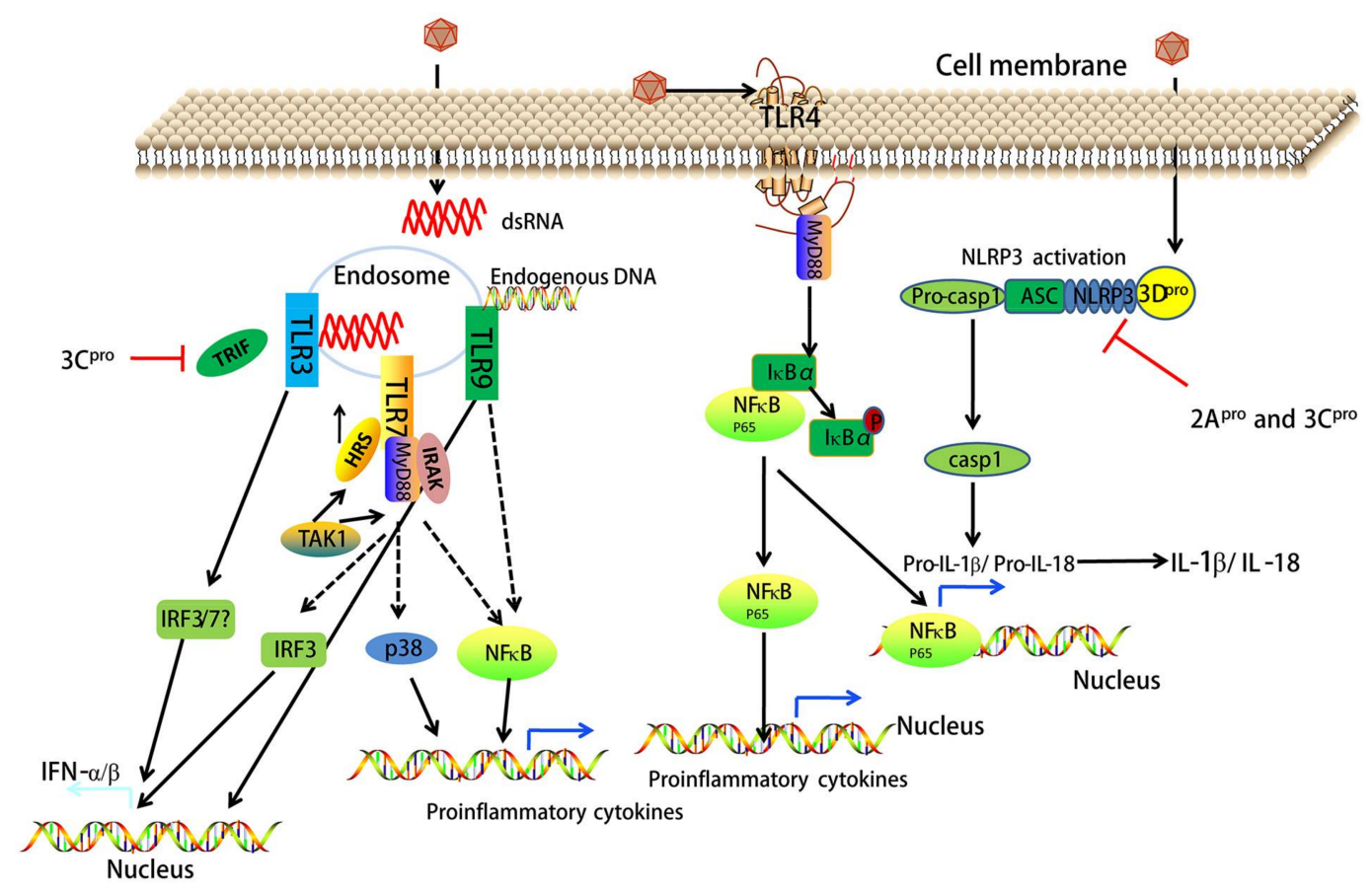

Figure 4. EV71 directly influences antiviral innate immunity and inflammatory responses by targeting pattern recognition receptors (PRRs). TLRs and NOD-like receptors (NLRs) belong to PRRs that sense lipids, lipoproteins, or peptidoglycans from bacteria, fungi, or protozoa, namely pathogen-associated molecular patterns (PAMPs). Additionally, these PRRs sense bacterial and viral nucleic acids, termed damage-associated molecular patterns (DAMPs). Endosomal TLR3 and TLR7

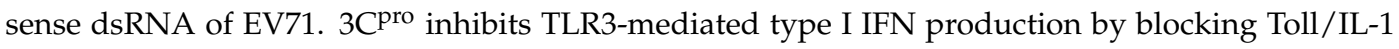
Receptor domain-containing adaptor inducing IFN- $\beta$ (TRIF). The interaction between hepatocyte growth factor-regulated tyrosine kinase substrate (HRS) and TAK1 regulates the ESCRT-0 complex and endosomal sorting of membrane proteins. HRS facilitates TLR7/NF- kB/p38 and TLR7/NF-kB/IRF3 signaling to produce proinflammatory cytokines and interferons during EV71 infection. Unlike TLR3 and TLR7, TLR9 senses endogenous DNA, and then mediates type I IFN production and NF- $\mathrm{B}$ activation. EV71 infection also activates TLR4/myeloid differentiation primary response 88 (MyD88)-dependent NF- $\mathrm{KB}$ signaling, which induces multiple proinflammatory cytokines including pro-IL-1 $\beta$ and pro-IL-18. 3D pro controls the assembly of the NLRP3 inflammasome that consists of pro-caspase-1 (casp1), ASC, and NLR family pyrin domain containing protein-3 (NLRP3). When activated, pro-casp 1 matures into casp1 that cleaves pro-IL-1 $\beta$ and pro-IL-18 to become the mature IL-1 $\beta$ and IL-18 proteins. $2 A^{\text {pro }}$ and $3 C^{\text {pro }}$ can inhibit NLRP3 inflammasome activation.

\section{EV71-Associated NOD-Like Receptor (NLR) Signaling}

NLRs, members of the pattern recognition receptor (PRR) family, are cytosolic counterparts of TLRs, which sense intracellular PAMPs and DAMPs [61]. Activation of some NLRs leads to the assembly of inflammasomes, which are large multiprotein complexes mediating the activation of inflammatory caspases. The best known inflammasome-forming NLRs are NLR family pyrin domain containing protein-1 (NLRP1), NLRP3, and NLR family caspase recruitment domain-containing protein-4 (NLRC4) [62]. Increasing evidence suggests that EV71 infection triggers inflammasome-mediated signaling [63-65]. EV71 3D pro interacts with NLRP3 to facilitate the assembly of inflammasome complexes by forming a 3D pro-NLRP3-ASC ring-like structure, which results in the activation of interleukin (IL)-1 $\beta$ [63]. While another study indicated that EV71 counteracts inflammasome activation through the cleavage of NLRP3 by $2 \mathrm{~A}^{\text {pro }}$ and $3 \mathrm{C}^{\text {pro }}$ [65]. Additionally, this

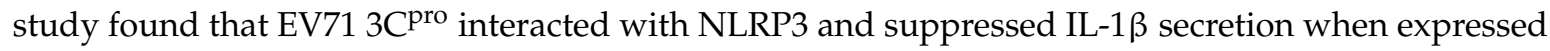
in mammalian cells [65]. IL-1 $\beta$ and IL-18 are regulated by inflammasome activation (e.g., NLRP3 
inflammasome) [62]. A recent study found that IL-18 exhibited a protective role against EV71 infection in mice, and administration of recombinant IL-18 could reverse EV71 infection-induced pathogenesis in vivo [64]. Overall, EV71 infection induces NLRP3 activation-associated signaling pathways, which may further regulate inflammatory responses and antiviral innate immunity (see Figure 4).

\section{EV71 Infection Activates Epidermal Growth Factor Receptor (EGFR) Signaling}

EGFR belongs to a family of receptor tyrosine kinases which includes three other members (erbB2/HER-2, erbB3/HER-3, and erbB4/HER-4). EGFR is anchored in the cytoplasmic membrane and composed of an extracellular ligand-binding domain, a short hydrophobic transmembrane region, and an intracytoplasmic tyrosine kinase domain. EGFR becomes activated by receptor overexpression (mainly in cancer) as well as ligand-dependent and ligand-independent mechanisms in response to a variety of stimuli [66]. It has been widely appreciated that EGFR-dependent signaling plays an important role in the pathogenesis of inflammation through regulation of pro-inflammatory genes $[67,68]$. The cytoplasmic Src (c-Src) kinase is known to trans-activate EGFR. It has been shown that EV71 infection stimulates cyclooxygenase-2 (COX-2) expression and prostaglandin E2 (PGE 2$)$ release following transactivation of EGFR by c-Src in EV71-infected cells [69]. Another study indicated that EV71 infection induces ROS generation and NADPH oxidase activation through integrin $\beta 1 / E G F R$, in turn modulating EV71 replication in SK-N-SH cells [70]. Additionally, the attenuation of the IFN signal pathway resulting from EGFR phosphorylation by reducing the expression of miR-27a might be one of the main reasons for the promotion of EV71 replication by the activation of MEK/ERK [71]. Thus, EV71 infection induces inflammatory responses and EV71 replication through EGFR signaling (see Figure 2).

\section{EV71 Activates Mitogen-Activated Protein Kinase (MAPK) Signaling}

The MAPK signaling pathway is the most characterized of all the signal transduction pathways. It regulates various physiological processes in cells-including inflammation, stress, cell growth, cell development, differentiation, and death-through multiple substrates including phosphorylated transcription factors and enzymes [72]. MAPK signal transduction occurs via sequential phosphorylation of MAPKKK (mitogen-activated protein kinase kinase kinase), MAPKK (mitogen-activated protein kinase kinase) and MAPK. To date, six MAPK sub-families have been identified in mammalian cells: JNK1/2/3, ERK1/2, p38MAPK (p38 $\alpha / \beta / \gamma / \delta)$, ERK7/8, ERK3/4 and ERK5/big MAP kinase 1 (BMK1) [73]. Many studies have indicated that MAPK pathways can be activated by EV71 infection [11,50,74-76]. Xie et al. reported that the p38, ERK1/2, and JNK1/2 pathways are activated during EV71 infection in human tonsillar epithelial cells, resulting in an over-expression of IL-8, IL-1 $\beta$, IL-6 and IL-12p40 [49]. Similar results were also found in human intestinal epithelial cells, vascular smooth muscle cells, and immature DCs $[52,75,77]$. EV71 infection activates both JNK1/2 and p38, with subsequent phosphorylation of downstream transcription factors c-Fos and c-Jun in immature DCs. This leads to enhanced production of IL-2, IL-6, IL-10, and TNF- $\alpha$. In addition, the administration of JNK1/2 and p38 inhibitors (e.g., SP600125 and SB203580) prevents EV71 replication and inflammatory cytokine production (e.g., IL-6, IL-10, and TNF- $\alpha$ ) [75]. PD169316, another p38 inhibitor, reduces EV71-induced apoptosis in vitro, implying the activation of p38 by EV71 infection [11]. In vivo experiments showed that PD169316 can inhibit the replication of EV71, reduce tissue damage, and block the release of proinflammatory cytokines (e.g., MCP-1 and TNF- $\alpha$ ) [11]. Similarly, another study reported that EV71 infection led to intrinsic apoptosis and induction of p38-mediated proinflammatory cytokines in human astrocytes [78]. Leong et al. found that the phosphorylation of p38 was stimulated by EV71 infection following misshapen/ Nck-interacting kinase (NIK)-related kinase (MINK) activation [76]. TAK1 is a member of MAPKKK. $3 C^{\text {pro }}$ can influence TAK1 complex proteins to suppress EV71 infection-induced cytokine production. Therefore, on the one hand, EV71 infection triggers inflammatory response through activating MAPK pathways [79,80]. On the other hand, EV71 may inhibit MAPK pathways (TAK1 signaling) to interact with inflammatory response (see Figure 2). 


\section{EV71 Induces Phosphatidylinositol 3-Kinase (PI3K) Signaling}

PI3K signaling is known to regulate cellular proliferation and growth [81], and play a critical role in triggering inflammatory reactions through the activation of the downstream protein kinase Akt $[82,83]$. It has been suggested that EV71 activates the PI3K/Akt pathway which further regulates proinflammatory cytokine transcription (e.g., IL-8, IL-1 $\beta$, IL-6 and IL-12p40) [49]. Activation of $\mathrm{PI} 3 \mathrm{~K} /$ Akt may be associated with the secretion of inflammatory cytokines in human RD cells [84,85]. EV71-induced Akt phosphorylation is associated with a PI3K-dependent mechanism [86]. Wortmannin, a PI3K-specific inhibitor, was shown to inhibit EV71 infection-induced PI3K/Akt activation in vascular smooth muscle cells [52]. Additionally, EV71-induced COX-2 expression and PGE2 production is mediated by the activation of a c-Src/PDGFR/PI3K/Akt/p42/p44 MAPK pathway to initiate the expression of a transcription factor of AP-1 in rat brain astrocytes [51]. In summary, EV71 infection can activate the PI3K/Akt pathway, further regulating inflammatory response (see Figure 2).

\section{EV71 Activates Calcium $\left(\mathrm{Ca}^{2+}\right)$-Dependent Signaling}

$\mathrm{Ca}^{2+}$ is a ubiquitous second messenger which regulates various reactions in eukaryotic cells [87]. A previous study demonstrated that elevated levels of mitochondrial $\mathrm{Ca}^{2+}$ are detected in EV71-infected cells, and calpain activation via $\mathrm{Ca}^{2+}$ flux plays an essential role in eliciting an apoptosis-inducing factor (AIF)-mediated, caspase-independent, apoptotic pathway during EV71 infection. Administration of ruthenium red, a mitochondrial $\mathrm{Ca}^{2+}$ influx inhibitor, significantly blocks calpain activation and AIF cleavage in EV71-infected cells [88]. Calmodulin-dependent protein kinase II (CaMKII) is necessary for $\mathrm{Ca}^{2+}$ homeostasis. The EV71 VP1 protein can activate CaMKII. If activated, it then phosphorylates the N-terminal domain of vimentin on serine 82 , and in turn plays a structural role for viral replication [89]. Taken together, EV71 infection facilitates EV71 replication and EV71-induced host cell apoptosis by activating $\mathrm{Ca}^{2+}$ - dependent signaling (see Figure 2).

\section{Conclusions and Future Perspectives}

In summary, antiviral and inflammatory cellular signaling pathways play a critical role in EV71-induced pathogenesis. It is apparent that RLRs, TLRs, and NLRs sense dsRNA or endogenous DNA derived from EV71 and EV71-induced host cell death to initiate antiviral innate immunity and inflammatory response by inducing downstream IRF-dependent signaling and/or NF- $\mathrm{B}$ signaling. EV71-encoded proteases are antagonists of IFN, RIG-I, MDA5, IRF, TLR, and NLR-dependent signaling pathways, which provides the molecular mechanisms for evasion of the innate immune response during EV71 infection. Future research is required to uncover more details surrounding the nucleation of RLR signaling at the interface between the mitochondria and mitochondria-associated membranes. These future studies will likely identify new mitochondrial molecules that regulate MAVS signaling. A more in-depth understanding of the mechanisms by which TLRs and NLRs function as both signaling molecules and antiviral effectors will promote a clearer characterization of the interplay between PRRs and the innate immune system. Given the limited clinical studies and in vivo studies, we cannot conclude that controlling $2 \mathrm{~A}^{\text {pro }}, 2 \mathrm{C}^{\text {pro }}, 3 \mathrm{C}^{\text {pro }}$, and $3 \mathrm{D}^{\text {pro }}$ synthesis, and dsRNA accumulation are underlying antiviral strategies for EV71 infection-associated HFMD. Additionally, the evidence linking $3 C^{\text {pro }}$ with RIG-I and MDA5 is not clear yet. Further structural and functional characterizations of EV71 proteins are needed to understand how these viral virulence factors interact with the human immune system, which will be useful in developing a vaccine. Further understanding of these interactions, which future research should prioritize, will lead to broad implications for clinicians and overall improvements in public health as we grapple with the burdens of HFMD-derived morbidity and mortality.

On the other hand, EV71 infection induces host cell ROS accumulation which activates specific cell surface receptors (e.g., EGFR), intracellular kinases (e.g., MAPK, PI3K), and transcription factors (e.g., NF-kB, AP-1) to induce proinflammatory cytokine production. Additionally, $\mathrm{Ca}^{2+}$-dependent 
signaling is required for EV71-induced host cell apoptosis and EV71 replication. Further research is required to uncover more details surrounding the nucleation of RLR signaling at the interface between the mitochondria and mitochondria-associated membranes, which will probably identify new mitochondrial molecules that regulate MAVS signaling. A more in-depth understanding of the mechanisms by which TLRs and NLRs function as both signaling molecules and antiviral effectors will promote a clearer characterization of the interplay between PRRs and the innate immune system. In addition, further investigation into the regulation of mitochondria-derived ROS during EV71 infection is warranted, as these molecules appear to influence several important aspects of inflammatory response. The cytokine storm has been confirmed in the process of EV71 infection-severe inflammatory syndrome (e.g., brainstem encephalitis, aseptic meningitis, encephalitis, acute flaccid paralysis, myocarditis, and even fatal pulmonary edema) [1]. Whether these local inflammatory responses come from EV71 infection-induced inflammatory cellular signaling pathways or immune cell response is not fully clarified. The cross effect of proinflammatory cytokines derived from immune cell response and inflammatory cellular signaling pathways may increase pulmonary vascular permeability, and even edema. The manner in which these findings will inform specific anti-inflammation strategies, thus far rather generically targeted, will be another field for ongoing investigation and innovation. Additionally, finding out whether $\mathrm{Ca}^{2+}$-dependent signaling affects skeletal muscle cell and cardiomyocyte function will be useful to reveal the novel mechanism underlying EV71 infection-induced muscle damage and cardiac disease.

Acknowledgments: We thank Jonathan Poe of Duke University Medical Center for the article's edition. This work was funded by the National Natural Science Foundation of China (81172740) and (81573205); key scientific research projects in Colleges and Universities of Henan Province (15A330003); and the Outstanding Doctoral Thesis Training Fund of Zhengzhou University.

Author Contributions: Yuefei Jin collected the references and wrote this manuscript. Rongguang Zhang, Weidong Wu, and Guangcai Duan critically reviewed and revised the article. All authors contributed to article's edits and approved the final manuscript.

Conflicts of Interest: The authors declare no conflict of interest.

\section{References}

1. Solomon, T.; Lewthwaite, P.; Perera, D.; Cardosa, M.J.; McMinn, P.; Ooi, M.H. Virology, epidemiology, pathogenesis, and control of enterovirus 71. Lancet Infect. Dis. 2010, 10, 778-790. [CrossRef]

2. Ooi, M.H.; Wong, S.C.; Lewthwaite, P.; Cardosa, M.J.; Solomon, T. Clinical features, diagnosis, and management of enterovirus 71. Lancet Neurol. 2010, 9, 1097-1105. [CrossRef]

3. Plevka, P.; Perera, R.; Cardosa, J.; Kuhn, R.J.; Rossmann, M.G. Crystal structure of human enterovirus 71. Science 2012, 336, 1274. [CrossRef] [PubMed]

4. Wang, X.; Peng, W.; Ren, J.; Hu, Z.; Xu, J.; Lou, Z.; Li, X.; Yin, W.; Shen, X.; Porta, C.; et al. A sensor-adaptor mechanism for enterovirus uncoating from structures of EV71. Nat. Struct. Mol. Biol. 2012, 19, 424-429. [CrossRef] [PubMed]

5. Notkins, A.L.; Oldstone, M. Concepts in Viral Pathogenesis I. Q. Rev. Biol. 1986, 60, 720-721.

6. Pathinayake, P.S.; Hsu, A.C.; Wark, P.A. Innate immunity and immune evasion by enterovirus 71 . Viruses 2015, 7, 6613-6630. [CrossRef] [PubMed]

7. Dang, D.; Zhang, C.; Zhang, R.; Wu, W.; Chen, S.; Ren, J.; Zhang, P.; Zhou, G.; Feng, D.; Sun, T. Involvement of inducible nitric oxide synthase and mitochondrial dysfunction in the pathogenesis of enterovirus 71 infection. Oncotarget 2017, 8, 81014-81026. [CrossRef] [PubMed]

8. Zhang, Y.; Cui, W.; Liu, L.; Wang, J.; Zhao, H.; Liao, Y.; Na, R.; Dong, C.; Wang, L.; Xie, Z.; et al. Pathogenesis study of enterovirus 71 infection in rhesus monkeys. Lab. Investig. 2011, 91, 1337-1350. [CrossRef] [PubMed]

9. Duan, G.; Yang, H.; Shi, L.; Sun, W.; Sui, M.; Zhang, R.; Wang, X.; Wang, F.; Zhang, W.; Xi, Y.; et al. Serum inflammatory cytokine levels correlate with hand-foot-mouth disease severity: A nested serial case-control study. PLoS ONE 2014, 9, e112676. [CrossRef] [PubMed] 
10. Jin, Y.; Zhang, C.; Zhang, R.; Ren, J.; Chen, S.; Sui, M.; Zhou, G.; Dang, D.; Zhu, J.; Feng, H.; et al. Pulmonary edema following central nervous system lesions induced by a non- mouse-adapted EV71 strain in neonatal BALB/c mice. Virol. J. 2017, 14, 243. [CrossRef] [PubMed]

11. Zhang, Z.; Wang, B.; Wu, S.; Wen, Y.; Wang, X.; Song, X.; Zhang, J.; Hou, L.; Chen, W. Pd169316, a specific p38 inhibitor, shows antiviral activity against enterovirus71. Virology 2017, 508, 150-158. [CrossRef] [PubMed]

12. Wen, T.; Xu, W.; Liang, L.; Li, J.; Ding, X.; Chen, X.; Hu, J.; Lv, A.; Li, X. Clinical efficacy of andrographolide sulfonate in the treatment of severe hand, foot, and mouth disease (HFMD) is dependent upon inhibition of neutrophil activation. Phytother. Res. PTR 2015, 29, 1161-1167. [CrossRef] [PubMed]

13. Hsiao, H.B.; Chou, A.H.; Lin, S.I.; Chen, I.H.; Lien, S.P.; Liu, C.C.; Chong, P.; Liu, S.J. Toll-like receptor 9-mediated protection of enterovirus 71 infection in mice is due to the release of danger-associated molecular patterns. J. Virol. 2014, 88, 11658-11670. [CrossRef] [PubMed]

14. Zhu, K.; Yang, J.; Luo, K.; Yang, C.; Zhang, N.; Xu, R.; Chen, J.; Jin, M.; Xu, B.; Guo, N.; et al. TLR3 signaling in macrophages is indispensable for the protective immunity of invariant natural killer $\mathrm{T}$ cells against enterovirus 71 infection. PLoS Pathog. 2015, 11, e1004613. [CrossRef] [PubMed]

15. Zhang, H.; Gomez, A.M.; Wang, X.; Yan, Y.; Zheng, M.; Cheng, H. Ros regulation of microdomain Ca ${ }^{2+}$ signalling at the dyads. Cardiovasc. Res. 2013, 98, 248-258. [CrossRef] [PubMed]

16. Zhang, J.; Wang, X.; Vikash, V.; Ye, Q.; Wu, D.; Liu, Y.; Dong, W. Ros and ros-mediated cellular signaling. Oxidative Med. Cell. Longev. 2016, 2016. [CrossRef] [PubMed]

17. Cheng, M.L.; Weng, S.F.; Kuo, C.H.; Ho, H.Y. Enterovirus 71 induces mitochondrial reactive oxygen species generation that is required for efficient replication. PLoS ONE 2014, 9, e113234. [CrossRef] [PubMed]

18. Ho, H.Y.; Cheng, M.L.; Weng, S.F.; Chang, L.; Yeh, T.T.; Shih, S.R.; Chiu, D.T. Glucose-6-phosphate dehydrogenase deficiency enhances enterovirus 71 infection. J. Gen. Virol. 2008, 89, 2080-2089. [CrossRef] [PubMed]

19. Chen, S.G.; Cheng, M.L.; Chen, K.H.; Horng, J.T.; Liu, C.C.; Wang, S.M.; Sakurai, H.; Leu, Y.L.; Wang, S.D.; Ho, H.Y. Antiviral activities of schizonepeta tenuifolia briq. against enterovirus 71 in vitro and in vivo. Sci. Rep. 2017, 7, 935. [CrossRef] [PubMed]

20. Qin, Y.; Lin, L.; Chen, Y.; Wu, S.; Si, X.; Wu, H.; Zhai, X.; Wang, Y.; Tong, L.; Pan, B.; et al. Curcumin inhibits the replication of enterovirus 71 in vitro. Acta Pharm. Sin. B 2014, 4, 284-294. [CrossRef] [PubMed]

21. Lv, X.; Qiu, M.; Chen, D.; Zheng, N.; Jin, Y.; Wu, Z. Apigenin inhibits enterovirus 71 replication through suppressing viral ires activity and modulating cellular JNK pathway. Antivir. Res. 2014, 109, 30-41. [CrossRef] [PubMed]

22. Yoneyama, M.; Kikuchi, M.; Natsukawa, T.; Shinobu, N.; Imaizumi, T.; Miyagishi, M.; Taira, K.; Akira, S.; Fujita, T. The RNA helicase RIG-I has an essential function in double-stranded RNA-induced innate antiviral responses. Nat. Immunol. 2004, 5, 730-737. [CrossRef] [PubMed]

23. Chan, Y.K.; Gack, M.U. RIG-I-like receptor regulation in virus infection and immunity. Curr. Opin. Virol. 2015, 12, 7-14. [CrossRef] [PubMed]

24. Goubau, D.; Deddouche, S.; Reis e Sousa, C. Cytosolic sensing of viruses. Immunity 2013, 38, 855-869. [CrossRef] [PubMed]

25. Lei, X.; Liu, X.; Ma, Y.; Sun, Z.; Yang, Y.; Jin, Q.; He, B.; Wang, J. The 3C protein of enterovirus 71 inhibits retinoid acid-inducible gene I-mediated interferon regulatory factor 3 activation and type i interferon responses. J. Virol. 2010, 84, 8051-8061. [CrossRef] [PubMed]

26. Lei, X.; Sun, Z.; Liu, X.; Jin, Q.; He, B.; Wang, J. Cleavage of the adaptor protein trif by enterovirus 71 3C inhibits antiviral responses mediated by toll-like receptor 3. J. Virol. 2011, 85, 8811-8818. [CrossRef] [PubMed]

27. Xu, C.; He, X.; Zheng, Z.; Zhang, Z.; Wei, C.; Guan, K.; Hou, L.; Zhang, B.; Zhu, L.; Cao, Y.; et al. Downregulation of microRNA miR-526a by enterovirus inhibits RIG-I-dependent innate immune response. J. Virol. 2014, 88, 11356-11368. [CrossRef] [PubMed]

28. Kuo, R.L.; Kao, L.T.; Lin, S.J.; Wang, R.Y.; Shih, S.R. MDA5 plays a crucial role in enterovirus 71 RNA-mediated IRF3 activation. PLoS ONE 2013, 8, e63431. [CrossRef] [PubMed]

29. Feng, Q.; Langereis, M.A.; Lork, M.; Nguyen, M.; Hato, S.V.; Lanke, K.; Emdad, L.; Bhoopathi, P.; Fisher, P.B.; Lloyd, R.E.; et al. Enterovirus 2Apro targets MDA5 and MAVS in infected cells. J. Virol. 2014, 88, 3369-3378. [CrossRef] [PubMed] 
30. Raisch, J.; Darfeuille-Michaud, A.; Nguyen, H.T. Role of microRNAs in the immune system, inflammation and cancer. World J. Gastroenterol. 2013, 19, 2985-2996. [CrossRef] [PubMed]

31. Chen, S.; Yang, Y.; Xu, J.; Su, L.; Wang, W. Effect of all-trans-retinoic acid on enterovirus 71 infection in vitro. Br. J. Nutr. 2014, 111, 1586-1593. [CrossRef] [PubMed]

32. Alvarez, C.E. On the origins of arrestin and rhodopsin. BMC Evolut. Biol. 2008, 8, 222. [CrossRef] [PubMed]

33. Meng, J.; Yao, Z.; He, Y.; Zhang, R.; Zhang, Y.; Yao, X.; Yang, H.; Chen, L.; Zhang, Z.; Zhang, H.; et al. ARRDC4 regulates enterovirus 71-induced innate immune response by promoting $\mathrm{K} 63$ polyubiquitination of MDA5 through TRIM65. Cell Death Dis. 2017, 8, e2866. [CrossRef] [PubMed]

34. Seth, R.B.; Sun, L.; Ea, C.K.; Chen, Z.J. Identification and characterization of MAVS, a mitochondrial antiviral signaling protein that activates NF-KB and IRF 3. Cell 2005, 122, 669-682. [CrossRef] [PubMed]

35. Wang, B.; Xi, X.; Lei, X.; Zhang, X.; Cui, S.; Wang, J.; Jin, Q.; Zhao, Z. Enterovirus 71 protease 2Apro targets MAVS to inhibit anti-viral type i interferon responses. PLoS Pathog. 2013, 9, e1003231. [CrossRef] [PubMed]

36. Platanias, L.C. Mechanisms of type-i- and type-ii-interferon-mediated signalling. Nat. Rev. Immunol. 2005, 5, 375-386. [CrossRef] [PubMed]

37. Darnell, J.E., Jr.; Kerr, I.M.; Stark, G.R. Jak-STAT pathways and transcriptional activation in response to IFNs and other extracellular signaling proteins. Science 1994, 264, 1415-1421. [CrossRef] [PubMed]

38. Lu, J.; Yi, L.; Zhao, J.; Yu, J.; Chen, Y.; Lin, M.C.; Kung, H.F.; He, M.L. Enterovirus 71 disrupts interferon signaling by reducing the level of interferon receptor 1. J. Virol. 2012, 86, 3767-3776. [CrossRef] [PubMed]

39. Wang, L.C.; Chen, S.O.; Chang, S.P.; Lee, Y.P.; Yu, C.K.; Chen, C.L.; Tseng, P.C.; Hsieh, C.Y.; Chen, S.H.; Lin, C.F. Enterovirus 71 proteins $2 \mathrm{~A}$ and 3D antagonize the antiviral activity of $\gamma$ interferon via signaling attenuation. J. Virol. 2015, 89, 7028-7037. [CrossRef] [PubMed]

40. Liao, C.C.; Liou, A.T.; Chang, Y.S.; Wu, S.Y.; Chang, C.S.; Lee, C.K.; Kung, J.T.; Tu, P.H.; Yu, Y.Y.; Lin, C.Y.; et al. Immunodeficient mouse models with different disease profiles by in vivo infection with the same clinical isolate of enterovirus 71. J. Virol. 2014, 88, 12485-12499. [CrossRef]

41. Song, J.; Hu, Y.; Li, J.; Zheng, H.; Wang, J.; Guo, L.; Shi, H.; Liu, L. Suppression of the toll-like receptor 7-dependent type $\mathrm{i}$ interferon production pathway by autophagy resulting from enterovirus 71 and coxsackievirus A16 infections facilitates their replication. Arch. Virol. 2018, 163, 135-144. [CrossRef] [PubMed]

42. Tamura, T.; Yanai, H.; Savitsky, D.; Taniguchi, T. The IRF family transcription factors in immunity and oncogenesis. Ann. Rev. Immunol. 2008, 26, 535-584. [CrossRef] [PubMed]

43. Janeway, C.A., Jr.; Medzhitov, R. Innate immune recognition. Ann. Rev. Immunol. 2002, 20, $197-216$. [CrossRef] [PubMed]

44. Wang, C.; Ji, L.; Yuan, X.; Jin, Y.; Cardona, C.J.; Xing, Z. Differential regulation of TLR signaling on the induction of antiviral interferons in human intestinal epithelial cells infected with enterovirus 71. PLoS ONE 2016, 11, e0152177. [CrossRef] [PubMed]

45. Lei, X.; Xiao, X.; Xue, Q.; Jin, Q.; He, B.; Wang, J. Cleavage of interferon regulatory factor 7 by enterovirus 71 3C suppresses cellular responses. J. Virol. 2013, 87, 1690-1698. [CrossRef] [PubMed]

46. Baldwin, A.S., Jr. The NF-кB and IкB proteins: New discoveries and insights. Ann. Rev. Immunol. 1996, 14, 649-683. [CrossRef] [PubMed]

47. Shen, H.M.; Tergaonkar, V. NF-кB signaling in carcinogenesis and as a potential molecular target for cancer therapy. Apoptosis 2009, 14, 348-363. [CrossRef] [PubMed]

48. Herrington, F.D.; Carmody, R.J.; Goodyear, C.S. Modulation of NF-kB signaling as a therapeutic target in autoimmunity. J. Biomol. Screen. 2015, 21, 223-242. [CrossRef] [PubMed]

49. Xie, G.C.; Guo, N.J.; Grenman, R.; Wang, H.; Wang, Y.; Vuorenmma, M.; Zhang, Q.; Zhang, S.; Li, H.Y.; Pang, L.L.; et al. Susceptibility of human tonsillar epithelial cells to enterovirus 71 with normal cytokine response. Virology 2016, 494, 108-118. [CrossRef] [PubMed]

50. Tung, W.H.; Hsieh, H.L.; Yang, C.M. Enterovirus 71 induces COX-2 expression via mapks, NF- $\mathrm{kB}$, and AP-1 in SK-N-SH cells: Role of $\mathrm{PGE}_{2}$ in viral replication. Cell Signal. 2010, 22, 234-246. [CrossRef] [PubMed]

51. Tung, W.H.; Lee, I.T.; Hsieh, H.L.; Yang, C.M. EV71 induces COX-2 expression via c-Src/PDGFR/PI3K/Akt/p42/p44 MAPK/AP-1 and NF- KB in rat brain astrocytes. J. Cell. Physiol. 2010, 224, 376-386. [CrossRef] [PubMed] 
52. Tung, W.H.; Sun, C.C.; Hsieh, H.L.; Wang, S.W.; Horng, J.T.; Yang, C.M. EV71 induces VCAM-1 expression via PDGF receptor, PI3-K/AKT, p38 MAPK, JNK and NF-KB in vascular smooth muscle cells. Cell Signal. 2007, 19, 2127-2137. [CrossRef] [PubMed]

53. Chang, C.Y.; Li, J.R.; Ou, Y.C.; Chen, W.Y.; Liao, S.L.; Raung, S.L.; Hsiao, A.L.; Chen, C.J. Enterovirus 71 infection caused neuronal cell death and cytokine expression in cultured rat neural cells. IUBMB Life 2015, 67, 789-800. [CrossRef] [PubMed]

54. Du, H.; Yin, P.; Yang, X.; Zhang, L.; Jin, Q.; Zhu, G. Enterovirus $712 \mathrm{C}$ protein inhibits NF-kB activation by binding to RelA(p65). Sci. Rep. 2015, 5, 14302. [CrossRef] [PubMed]

55. Zhang, L.; Li, Y.; Gu, Z.; Wang, Y.; Shi, M.; Ji, Y.; Sun, J.; Xu, X.; Jiang, J.; Shi, W. Resveratrol inhibits enterovirus 71 replication and pro-inflammatory cytokine secretion in rhabdosarcoma cells through blocking IKKs/NF-KB signaling pathway. PLoS ONE 2015, 10, e0116879.

56. Baccala, R.; Hoebe, K.; Kono, D.H.; Beutler, B.; Theofilopoulos, A.N. TLR-dependent and TLR-independent pathways of type i interferon induction in systemic autoimmunity. Nat. Med. 2007, 13, 543-551. [CrossRef] [PubMed]

57. Lin, Y.L.; Hu, Y.C.; Liang, C.C.; Lin, S.Y.; Liang, Y.C.; Yuan, H.P.; Chiang, B.L. Enterovirus-71 virus-like particles induce the activation and maturation of human monocyte-derived dendritic cells through TLR4 signaling. PLoS ONE 2014, 9, e111496. [CrossRef] [PubMed]

58. Luo, Z.; Ge, M.; Chen, J.; Geng, Q.; Tian, M.; Qiao, Z.; Bai, L.; Zhang, Q.; Zhu, C.; Xiong, Y.; et al. HRS plays an important role for TLR7 signaling to orchestrate inflammation and innate immunity upon EV71 infection. PLoS Pathog. 2017, 13, e1006585. [CrossRef] [PubMed]

59. Zhu, L.; Li, W.; Qi, G.; Liu, N.; Sheng, L.; Shang, L.; Qi, B. The immune mechanism of intestinal tract toll-like receptor in mediating EV71 virus type severe hand-foot-and-mouth disease and the mapk pathway. Exp. Ther. Med. 2017, 13, 2263-2266. [CrossRef] [PubMed]

60. Gong, X.; Zhou, J.; Zhu, W.; Liu, N.; Li, J.; Li, L.; Jin, Y.; Duan, Z. Excessive proinflammatory cytokine and chemokine responses of human monocyte-derived macrophages to enterovirus 71 infection. BMC Infect. Dis. 2012, 12, 224. [CrossRef] [PubMed]

61. Shaw, P.J.; McDermott, M.F.; Kanneganti, T.D. Inflammasomes and autoimmunity. Trends Mol. Med. 2011, 17, 57-64. [CrossRef] [PubMed]

62. Broz, P.; Dixit, V.M. Inflammasomes: Mechanism of assembly, regulation and signalling. Nat. Rev. Immunol. 2016, 16, 407-420. [CrossRef] [PubMed]

63. Wang, W.; Xiao, F.; Wan, P.; Pan, P.; Zhang, Y.; Liu, F.; Wu, K.; Liu, Y.; Wu, J. EV71 3D protein binds with NLRP3 and enhances the assembly of inflammasome complex. PLoS Pathog. 2017, 13, e1006123. [CrossRef] [PubMed]

64. Li, Z.; Wang, H.; Chen, Y.; Niu, J.; Guo, Q.; Leng, Q.; Huang, Z.; Deng, Z.; Meng, G. Interleukin-18 protects mice from enterovirus 71 infection. Cytokine 2017, 96, 132-137. [CrossRef] [PubMed]

65. Wang, H.; Lei, X.; Xiao, X.; Yang, C.; Lu, W.; Huang, Z.; Leng, Q.; Jin, Q.; He, B.; Meng, G.; et al. Reciprocal regulation between enterovirus 71 and the NLRP3 inflammasome. Cell Rep. 2015, 12, 42-48. [CrossRef] [PubMed]

66. Polosa, R.; Sapsford, R.J.; Dokic, D.; Cacciola, R.R.; Prosperini, G.; Devalia, J.L.; Holgate, S.T.; Howarth, P.H.; Davies, D.E. Induction of the epidermal growth factor receptor and its ligands in nasal epithelium by ozone. J. Allergy Clin. Immunol. 2004, 113, 120-126. [CrossRef] [PubMed]

67. Wu, W.; Wages, P.A.; Devlin, R.B.; Diaz-Sanchez, D.; Peden, D.B.; Samet, J.M. SRC-mediated EGF receptor activation regulates ozone-induced interleukin 8 expression in human bronchial epithelial cells. Environ. Health Perspect. 2015, 123, 231-236. [CrossRef] [PubMed]

68. Feng, F.; Jin, Y.; Duan, L.; Yan, Z.; Wang, S.; Li, F.; Liu, Y.; Samet, J.M.; Wu, W. Regulation of ozone-induced lung inflammation by the epidermal growth factor receptor in mice. Environ. Toxicol. 2015. [CrossRef] [PubMed]

69. Tung, W.H.; Hsieh, H.L.; Lee, I.T.; Yang, C.M. Enterovirus 71 modulates a COX-2/PGE2/cAMP-dependent viral replication in human neuroblastoma cells: Role of the c-Src/EGFR/p42/p44 MAPK/CREB signaling pathway. J. Cell. Biochem. 2011, 112, 559-570. [CrossRef] [PubMed]

70. Tung, W.H.; Hsieh, H.L.; Lee, I.T.; Yang, C.M. Enterovirus 71 induces integrin $\beta 1 /$ EGFR-Rac1-dependent oxidative stress in SK-N-SH cells: Role of HO-1/CO in viral replication. J. Cell. Physiol. 2011, 226, 3316-3329. [CrossRef] [PubMed] 
71. Zhang, L.; Chen, X.; Shi, Y.; Zhou, B.; Du, C.; Liu, Y.; Han, S.; Yin, J.; Peng, B.; He, X.; et al. mir-27a suppresses EV71 replication by directly targeting EGFR. Virus Genes 2014, 49, 373-382. [CrossRef] [PubMed]

72. Bogoyevitch, M.A.; Kobe, B. Uses for JNK: The many and varied substrates of the c-Jun N-terminal kinases. Microbiol. Mol. Biol. Rev. 2006, 70, 1061-1095. [CrossRef] [PubMed]

73. Krishna, M.; Narang, H. The complexity of mitogen-activated protein kinases (MAPKs) made simple. Cell. Mol. Life Sci. 2008, 65, 3525-3544. [CrossRef] [PubMed]

74. Bian, L.; Wang, Y.; Liu, Q.; Xia, J.; Long, J.E. Prediction of signaling pathways involved in enterovirus 71 infection by algorithm analysis based on miRNA profiles and their target genes. Arch. Virol. 2015, 160, 173-182. [CrossRef] [PubMed]

75. Peng, H.; Shi, M.; Zhang, L.; Li, Y.; Sun, J.; Wang, X.; Xu, X.; Zhang, X.; Mao, Y.; Ji, Y.; et al. Activation of JNK1/2 and p38 MAPK signaling pathways promotes enterovirus 71 infection in immature dendritic cells. BMC Microbiol. 2014, 14, 147. [CrossRef] [PubMed]

76. Leong, S.Y.; Ong, B.K.; Chu, J.J. The role of misshapen NCK-related kinase (MINK), a novel Ste20 family kinase, in the IRES-mediated protein translation of human enterovirus 71. PLoS Pathog. 2015, 11, e1004686. [CrossRef] [PubMed]

77. Wang, C.; Gao, L.; Jin, Y.; Cardona, C.J.; Xing, Z. Regulation of host responses and viral replication by the mitogen-activated protein kinases in intestinal epithelial cells infected with enterovirus 71. Virus Res. 2015, 197, 75-84. [CrossRef] [PubMed]

78. Wang, C.; Zhou, R.; Zhang, Z.; Jin, Y.; Cardona, C.J.; Xing, Z. Intrinsic apoptosis and proinflammatory cytokines regulated in human astrocytes infected with enterovirus 71. J. Gen. Virol. 2015, 96, 3010-3022. [CrossRef] [PubMed]

79. Ono, K.; Ohtomo, T.; Sato, S.; Sugamata, Y.; Suzuki, M.; Hisamoto, N.; Ninomiya-Tsuji, J.; Tsuchiya, M.; Matsumoto, K. An evolutionarily conserved motif in the TAB1 C-terminal region is necessary for interaction with and activation of TAK1 MAPKKK. J. Biol. Chem. 2001, 276, 24396-24400. [CrossRef] [PubMed]

80. Lei, X.; Han, N.; Xiao, X.; Jin, Q.; He, B.; Wang, J. Enterovirus 71 3C inhibits cytokine expression through cleavage of the TAK1/TAB1/TAB2/TAB3 complex. J. Virol. 2014, 88, 9830-9841. [CrossRef] [PubMed]

81. Cantley, L.C. The phosphoinositide 3-kinase pathway. Science 2002, 296, 1655-1657. [CrossRef] [PubMed]

82. Patel, R.K.; Mohan, C. PI3K/AKT signaling and systemic autoimmunity. Immunol. Res. 2005, 31, 47-55. [CrossRef]

83. Hawkins, P.T.; Stephens, L.R. PI3K signalling in inflammation. Biochim. Biophys. Acta 2015, 1851, 882-897. [CrossRef] [PubMed]

84. Shi, W.; Hou, X.; Li, X.; Peng, H.; Shi, M.; Jiang, Q.; Liu, X.; Ji, Y.; Yao, Y.; He, C.; et al. Differential gene expressions of the MAPK signaling pathway in enterovirus 71-infected rhabdomyosarcoma cells. Braz. J. Infect. Dis. 2013, 17, 410-417. [CrossRef] [PubMed]

85. Shi, W.; Li, X.; Hou, X.; Peng, H.; Jiang, Q.; Shi, M.; Ji, Y.; Liu, X.; Liu, J. Differential apoptosis gene expressions of rhabdomyosarcoma cells in response to enterovirus 71 infection. BMC Infect. Dis. 2012, 12, 327. [CrossRef] [PubMed]

86. Zhang, H.; Li, F.; Pan, Z.; Wu, Z.; Wang, Y.; Cui, Y. Activation of PI3K/Akt pathway limits JNK-mediated apoptosis during EV71 infection. Virus Res. 2014, 192, 74-84. [CrossRef] [PubMed]

87. Pchitskaya, E.; Popugaeva, E.; Bezprozvanny, I. Calcium signaling and molecular mechanisms underlying neurodegenerative diseases. Cell Calcium 2018, 70, 87-94. [CrossRef] [PubMed]

88. Lu, J.R.; Lu, W.W.; Lai, J.Z.; Tsai, F.L.; Wu, S.H.; Lin, C.W.; Kung, S.H. Calcium flux and calpain-mediated activation of the apoptosis-inducing factor contribute to enterovirus 71-induced apoptosis. J. Gen. Virol. 2013, 94, 1477-1485. [CrossRef] [PubMed]

89. Haolong, C.; Du, N.; Hongchao, T.; Yang, Y.; Wei, Z.; Hua, Z.; Wenliang, Z.; Lei, S.; Po, T. Enterovirus 71 VP1 activates calmodulin-dependent protein kinase ii and results in the rearrangement of vimentin in human astrocyte cells. PLoS ONE 2013, 8, e73900. [CrossRef] [PubMed]

(C) 2018 by the authors. Licensee MDPI, Basel, Switzerland. This article is an open access article distributed under the terms and conditions of the Creative Commons Attribution (CC BY) license (http:/ / creativecommons.org/licenses/by/4.0/). 